\title{
Estéticas de lo residual. Ruina, materialidad y escritura en Carlos Ríos
}

\author{
ANA NEUBURGER Universidad Nacional de Córdoba - CONICET, Argentina / ana.neuburger@gmail.com
}

\section{Resumen}

En la literatura argentina reciente es posible advertir hace ya algún tiempo la emergencia de espacios derruidos, de tiempos heterogéneos, de restos y desechos. Desde escenarios apocalípticos hasta el exceso de basura y escombros, lo residual adquiere relevancia y produce un desajuste en el imaginario estético contemporáneo. Quisiéramos leer este desplazamiento a partir de la figura de la ruina y el campo de relaciones que abre entre imagen, escritura, materialidad y tiempo. ¿De qué modo se reactivan los restos del pasado? ¿Qué lengua los nombra? ¿Qué procedimientos operan allí? Este trabajo explora en la escritura de Carlos Ríos - Manigua y Cuaderno de Pripyatel vínculo que establece con una serie de imágenes al borde de la descomposición. Ambas ficciones configuran un tiempo presente que se encuentra escindido, es decir, una temporalidad signada por los restos de un mundo fragmentario. La ruina, en este sentido, redefine el estado de la materia y del presente, ya que su aparición en el escenario contemporáneo revierte el diagnóstico decadente para afirmarse como la persistencia material del pasado en el presente.

Palabras clave: ruina / materialidad / imagen / temporalidad

\section{Aesthetics of the residual. Ruin, materiality and writing in Carlos Ríos}

Abstract

In the recent Argentine literature it is possible to note the emergence of demolished spaces, heterogeneous times, remnants and waste. From the apocalyptic scenarios to the excess of garbage and rubbish, the residual becomes relevant and produces a mismatch in the contemporary aesthetic imaginary. We would like to read this displacement from the figure of the ruin and the field of relations that opens between image, writing, materiality and time. How are the remains of the past reactivated? What language names them? What procedures operate there? This work explores in the writing of Carlos Ríos -Manigua and Cuaderno de Pripyat- the link that it establishes with a series of images on the edge of decomposition. Both fictions configure a present time that is split, or in other terms a temporality marked by the remains of a fragmentary world. Ruin, in this sense, redefines the state of matter and the present, since its appearance in the contemporary scenario reverses the decadent diagnosis to affirm itself as the material persistence of the past in the present.

Key words: ruin / materiality / image / temporality

Recibido: 1/3/2020. Aceptado: 3/4/2020

Para citar este artículo: Neuburger, A. (2020). Estéticas de lo residual. Ruina, materialidad y escritura en Carlos Ríos. El taco en la brea, 11 (diciembre-mayo), 123-132. Santa Fe, Argentina: UNL. DOI: 10.14409/tb. v1i11.9161 
Un exiliado — pero no cualquier exilio, sino uno producto del desastre mismo — regresa al lugar donde nació, una ciudad devastada por la radiación, cierra los ojos y emprende el camino hacia el hogar de su infancia, guiado solo por las imágenes del recuerdo. En su mirada convergen la imagen del pasado y la del presente derruido. Se encuentra con restos imposibles de componer. Ve una taza en el piso, la levanta y esta se deshace antes de llegar a sostenerla en sus manos.

Un colectivo avanza por el desierto, cruzando restos de ciudades y escombros. Se detiene ante una enorme roca blanca y todos los pasajeros bajan con picos y palas a cavar alrededor de ella. Es un fósil, que luego de horas de trabajo adquiere la forma del cráneo gigante de un roedor, el cual cargarán en el techo del colectivo para luego ser vendido. El colectivo cruza el desierto, con el fósil atado con sogas y palos, en dirección a una ciudad hecha de cartón, plástico y madera.

Entre los años 2009 y 2012 Carlos Ríos publica dos libros que sitúan en primer plano la cuestión de la ruina como imagen que condensa una serie de relaciones que atraviesan la literatura argentina contemporánea: la escenificación de espacios degradados, la discontinuidad como procedimiento para construir una imagen del mundo contemporáneo, el entramado de temporalidades para repensar el vínculo entre pasado y presente, la destrucción y la preservación, la presencia de materiales precarios y descartables. Ambas escenas provienen de Manigua y Cuaderno de Pripyat, y comienzan a exhibir el despliegue de escenarios en los que la catástrofe ya tuvo lugar y aun así hay un después, hay un relato por componer, hay restos. Las ruinas de la escritura de Ríos no son un rastro desprovisto de sentido, sino que «su excavación la hará ir relatando sus historias» (Blackmore:258). Como en Excavar y recordar, ese reconocido fragmento de Benjamin, donde la relación con el tiempo pasado toma la forma de una excavación, en la que el hombre esparce y revuelve la tierra, al encuentro con su pasado sepultado. Así sucede con los personajes de ambas ficciones: frente a escenarios en descomposición donde solo quedan restos por recomponer, se insiste en imaginar modos de permanencia e inscripción del presente.

En este sentido, la presencia de ruinas, restos y residuos en el campo de la literatura y las artes de los últimos años constituye un cambio en el imaginario estético. Su presencia ya no apunta a designar un estado de crisis permanente en torno a lo contemporáneo desde la configuración de un tiempo marcado principalmente por el fin, ni desde la mirada melancólica ante la pérdida del tiempo pasado, sino que señala una insistencia, un hacer con los restos de eso que ha quedado y con ellos una exploración de los alcances de ese tiempo que vino «después de». El desajuste que produce la aparición de restos en el imaginario estético se inscribe además en una preocupación más amplia sobre la temporalidad y el presente: «el tiempo está en el centro de las discusiones sobre "lo contemporáneo" que ha ocupado a la crítica durante los últimos años» (Speranza:18). La expansión de los debates acerca del tiempo y la historia que detecta Graciela Speranza, entre muchos otros críticos, consolidó no solo un modo de interrogar el sentido de los relatos progresivos y cronológicos, sino además otro modo de concebir la apertura y el entramado que compone el presente en relación con otros tiempos. ${ }^{1}$ Así, la idea de resto en la literatura, el arte y la crítica nombra otra articulación temporal con el presente, dando lugar a la emergencia de retornos, latencias, irrupciones, supervivencias. Allí donde nuestra época y nuestros modos de lo contemporáneo se encontraron asediados por múltiples crisis, advertimos también una marcada 
tendencia en escritores y artistas en indagar y reflexionar sobre las catástrofes de nuestro tiempo. ¿Qué sentidos se abren en la actualidad ante la presencia de estos escenarios en ruinas? ¿Y por qué volver a situarnos en estos paisajes heterogéneos, habiendo pasado ya el gran siglo de las destrucciones?² ${ }^{2}$ uizás en la actualidad la imagen de la ruina indica más el punto de partida y el lugar propicio desde donde relanzar un hacer, que el mero agotamiento o el lamento ante lo perdido.

La ruina, en tanto imagen de aquello que retorna, irrumpe como figuración temporal y material para perturbar el sentido de la historia, dispone otra lectura de los hechos del pasado y expresa una nueva potencia que se manifiesta en toda superficie que se inscriba. En este sentido, su aparición en el escenario contemporáneo impugna la clausura del tiempo histórico e interrumpe el diagnóstico decadente para manifestarse como resto que ha quedado pese a todo. En la noción de ruina se exhibe, ya no la inoperancia y la caída de los sentidos que traman nuestra época, sino una potencia activa como clave para pensar nuestro tiempo. En relación con esto, Mario Cámara lee la potencia del resto en el presente como el modo de contraponer los alcances del diagnóstico decadente de la historia: «Esa potencia y ese uso, sin embargo, no deben ser entendidos como restauración, sino más bien como reemergencia desplazada que escenifica un uso inaudito y una potencialidad desconocida» (16). Advertimos entonces en la noción de ruina una redefinición del estado de la materia y del presente que despunta el sentido de caducidad y conduce a descubrir en el paisaje contemporáneo los vestigios de todos los incendios de la historia (Didi-Huberman, 1997). La expresión de Didi-Huberman hace énfasis en el rastro que visibiliza la temporalidad de la ruina, esto es, en la persistencia material del trabajo del tiempo. En su carácter de huella, de marca temporal, la ruina emerge como una imagen enfrentada a todo lo que queda y a todo lo que perdió, como una imagen de aquello que ha sobrevivido a todas sus destrucciones. Si la lectura de Didi-Huberman se afirma en el gesto histórico y político de recuperar el detalle, la ruina aquí asiste al encuentro con una materia tenue, precaria en sus formas, espectral por momentos, pero que resiste ante el olvido y la destrucción.

En tanto resto, la ruina guarda una potencia actual que aún opera en el presente y expresa así la apertura del tiempo histórico: una exploración de los alcances del tiempo después. Esta nueva potencia nos sitúa en un escenario contemporáneo sin imaginación dramática alguna del fin, conformando un paisaje que, al suspender la agonía de los restos, hace de ellos la posibilidad misma de interrogación por el presente. Así, las transformaciones y desplazamientos que se dan al interior de la literatura de las últimas décadas propician una escritura que tiene como cometido revisar el paisaje heterogéneo que anteriormente pretendía recomponer (Rodríguez Freire). En este marco, la literatura descubre una nueva zona de exploración que trabaja con sobras, restos y desperdicios como cifra de una apuesta: «hay un resto de un objeto, no mucho tal vez, pero objeto al fin; y en sus anafructuosidades, en sus hendiduras, grietas, fisuras, se insinúa la memoria que lo eterniza. La memoria ama las resquebrajaduras. Tiene afición por la ruina» (Wacjman:15).

La imagen de la ruina manifiesta tanto la potencia del presente como su propio estado de crisis, esto es, un presente signado por los restos del mundo contemporáneo. Gérard Wajcmar asegura que la destrucción acosa nuestra época y además, que nuestra época es un inmenso campo de escombros. Y aun así hay restos, vestigios, huellas materiales. Por su parte, Eduardo Cadava insiste en que nuestra época está definida por imágenes, por inscripciones de todo tipo, y que a su vez, la ruina es el corazón de las imágenes, en tanto principio de representación que trabaja en toda imagen. Cadava nombra la relación entre ruina e imagen lapsus imaginis, a partir del movimiento de 
interrupción que supone la ocasión de cada imagen, a la vez que la ruina expone la interrupción del principio de presentación, esto es, la premisa fallida de la visualidad total. La ruina, en este sentido, enlaza destrucción y supervivencia, y lo que hace de ella una imagen es su capacidad de exhibir las huellas de lo que no puede mostrar, su capacidad arruinada de mostración.

La escritura de Ríos despliega un paisaje derruido en el que la ruina adquiere diversas formas, exponiendo un vínculo sostenido entre materialidad, imagen y procedimiento. En Manigua (2009) la transmisión del relato se vuelve la pauta de construcción y preservación de la memoria. Apolón le relata a su hermano enfermo la historia de cómo se convirtió en el líder de su clan con el propósito de encontrar una vaca para sacrificar el día de su nacimiento. La historia debe llegar a su fin para dar lugar a la muerte: «escucharé la historia del animal sacrificado el día de mi nacimiento y luego me iré en paz» (39). Hay no solo una urgencia en continuar el relato, en desplegar una historia amenazada por la muerte, sino también la configuración de un tiempo mítico propiciada por esa misma muerte y esa espera. De allí, el relato exhibe una condición inestable del tiempo y de la escritura. Incesantemente, los personajes de Manigua dibujan en la tierra palabras, historias, imágenes que luego serán polvo. O fuman y comienzan a soltar una mistura de humo y palabras. La palabra busca adquirir volumen, densidad, mezclarse, volverse material, aunque sea solo por un momento:

Apolón habló. El hermano sólo escucha palabras, cientos de palabras que se escapaban de la boca de Apolón, de mi boca a la cesta de mimbre donde mi hermano las recogía como si se tratase de peces moribundos, palabras, niños, machete, brazo, madriguera, mamíferos, gigantes, huesos, perezosos, punta, hermengo, playas, evidencias, cuevas, estructuras, sedimento, donise kangoro, roedores, armadillos, marcas, garras, palabras, extintos, peces, el hermano de Apolón se los llevaba a la boca, hasta dormirse, narcotizado por la voz de su hermano y el baile loco de las cestas de mimbre. (38)

Las ruinas que pueblan Manigua parecieran imponer una sintaxis particular, como si ese mundo desplazado, en continua variación, estuviera atravesado por una lengua en proceso de degradación, una lengua en ruinas. Así lo cuenta Apolón, en el momento previo a la muerte de su hermano: «En el corazón de la guerra, el swahili hablado por nuestros hermanos se había convertido en una lengua incomprensible. Se había teñido de vulgaridad, de consonantes que en boca de los miembros del clan golpeaban con la fuerza de un machete» (58). La lengua es «una identidad en riesgo» (51) que se repite y enlista en palabras que salen de la boca de Apolón para que no se disuelvan y caigan en el olvido, «palabras clave» que hacen que la memoria del hermano sobreviva al deterioro de su cuerpo. Son palabras de otro tiempo, palabras de la infancia, de un tiempo remoto que ya no nombran el estado actual de las cosas. Hacia el final, termina siendo «una lengua infernal» (59), cercana a la aniquilación de un pueblo y aun así tampoco es una lengua muerta, más bien es una lengua hecha de retazos, desfasada de su tiempo, que busca adherirse a las cosas, pronunciarse para seguir nombrando aquello que ya no está.

Hay una idea de inestabilidad que atraviesa toda la novela. El paisaje oscila entre el desierto y las construcciones precarias de las ciudades, ese es, precisamente, el modo en que comienza el relato: Muthahi observa en el medio del desierto una ciudad colapsada que sobrevive a partir de materiales 
descartables (cartón y plástico). Además, hay un relato desdoblado, a dos voces que se intercalan para narrar lo mismo, para contar dos historias, para hacer circular una palabra común. Por un lado, la transformación de Muthahi en Apolón, dada por el mandato familiar, y por el otro, narra tiempo después el encuentro de Muthahi y su hermano agonizante en donde se cuenta la primera historia. Ambos relatos se mezclan y superponen voces y tiempos disímiles. En la literatura que construye mundos posteriores a la debacle, subraya Francine Masiello, «predominan los personajes anónimos, el viaje incansable de los exiliados, donde nos cruzamos con un maremoto de sujetos nómades que pasan por paisajes baldíos» (2012:82). En Manigua, el desplazamiento de los personajes adquiere la forma de una deriva y hasta los lugares a los que se dirigen están en continua variación, desde el paso por el desierto hacia las ciudades hechas de basura: «Ubicada en una planicie, la ciudad parecía desmentirse a sí misma. Se hizo tan pequeña que podíamos levantarla en brazos. Tócala, dijo la mujer, y puse la mano en lo que parecía el hombro de una estatua o la columna de un edificio» (Ríos, 2009:23). Los materiales que circulan allí participan de esa transformación dada por su condición descartable, a la vez que su presencia desajusta el orden del relato primitivo. Porque Manigua yuxtapone tiempos disímiles, haciendo converger una historia originaria con televisores, celulares y residuos propios de la era del capitalismo tardío, a la vez que cruza temporalidades en el relato, del inicio del mandato de Apolón al presente de la muerte próxima del hermano, para hacia el final reducir la historia al transcurso de 25 días, tiempo que dura la exposición del antropólogo.

Las ciudades son de cartón, los templos y los muebles están construidos con tubos de plástico, los elementos cortantes son el cuello de una botella rota, todos estos materiales adquieren la forma de remanentes inútiles, reencauzados a un nuevo uso. El cartón se moja, los cuerpos están cubiertos de polvo: la materialidad resiste y a la vez cede ante el contacto, ante el tiempo y el espacio. Son materiales plásticos, en perpetuo devenir, reutilizables a pesar de su condición de residuo, de poca durabilidad.

Mientras avanza por el desierto, Apolón se encuentra con una mujer que se dedica a la demolición de casas, a la vez que enseña a usarlas a aquellas personas que desconocen el uso de una vivienda. Es en el desierto también donde Apolón se encuentra con piedras «como si fuesen materiales de una obra a medio terminar» (Ríos, 2009:36). El paisaje despliega un vínculo entre la destrucción, la materia y el fragmento. «Era verdaderamente la desolación hecha paisaje» (58), dice Apolón atravesando el campo. La naturaleza también se encuentra en un proceso de degradación. El sol es «una reliquia inútil» (51) que da frío y el agua contaminada es espesa, opaca y forma «fontales de mugre que jamás reflejarían el cielo» (26). El río es apenas un hilo borroso que se abre como una cicatriz en la tierra. El paisaje, en tanto trozo de la naturaleza (Simmel) supone una fragmentariedad allí donde la naturaleza se piensa como unidad. De ahí que ruina y paisaje se encuentren tan próximas, como operación de fragmentación de un mundo, como encuadre dirá Francine Masiello (2008), como emergencia de una imagen de la ruina. Es por eso que el escenario derruido que presenta Manigua, con los elementos transfigurados de la naturaleza, componen un paisaje en constante transformación y deterioro.

Algunos elementos residuales son recuperados y adquieren un nuevo uso, como los techos y ventanas que los saqueadores llevan para usarlos como pisos de sus viviendas, otros son relegados y olvidados. Sin embargo, todos parecen coincidir en su carácter de inutilidad, de resistencia y de resto, como la maleza que crece y se esparce en lugares indeseados. Decimos maleza ya que este es uno de los sentidos de Manigua y del propio término, que alude en la primera página ${ }^{3}$ a la abundancia, el desorden y la confusión, y a los terrenos pantanosos cubiertos de malezas. Quizás 
este estado caótico propio de la maleza podamos pensarlo en términos de aquello que resiste e insiste, hasta en los paisajes más desolados.

En las novelas de Ríos, el nombre se otorga y en un movimiento también se pierde, como si estuviéramos ante la construcción de una identidad volátil. Apolón, al comienzo, es Muthahi, pero para poder liderar su clan participa de un breve ritual que realiza su padre para tomar este nombre. Otros personajes también son Apolón, conformando así una especie de filiación común. Y hacia el final, Apolón pierde su nombre. Su hermano, a la espera de la muerte, no tiene nombre, sino que «se identifica con el primer nombre que escuche, y el único que ha oído desde hace años es el mío. Por un castigo de mi padre, mi hermano perdió la oportunidad de ser nombrado, incluso el día de su muerte» (2009:57). Así es que hacia el final, la muerte del hermano, acompasada al final del relato, participa de un hecho insólito. Tres finales se anticipan en el apartado 6o: la muerte del hermano, el final de la historia contada por Apolón y el fin de la exposición de un antropólogo la cual, con el hermano del protagonista y con espectadores incluidos, busca «mostrar la belleza de la muerte, la agonía en las salas de cuidados intensivos» (59). La sala del hospital se vuelve una escenografía en pleno desmontaje: «con mantas, cartones pintados de blanco y bolsas de suero se creó una atmósfera privada» (59). Y el antropólogo inglés pasa a ser un artista, figura presente en muchas ficciones de Ríos, que nos viene a indicar una vez más cómo el arte es una cuestión de resto. Hacia el final se articulan también distintos registros del relato que exhiben además la heterogeneidad como operación y procedimiento de la escritura de Ríos. Una vez concluida la muestra del antropólogo inglés, Apolón ya no cuenta la historia al hermano sino que la escribe y, en el apartado siguiente, habla frente a una cámara para la realización de un documental.

En Manigua no hay origen asignado al escenario de la destrucción, hecho que torna aún más difícil el reconocimiento de alguna marca epocal en la novela. En Cuaderno de Pripyat, en cambio, se explora un determinado modo de reorganización social que tiene lugar después de la reconocida explosión. Aquí, Malofienko vuelve a su ciudad luego del renombrado accidente nuclear de Chernobyl, y con el fin de realizar un documental, hecho que pasa casi inadvertido, registra todo lo que sucede: filma, sube videos a Youtube, pone pausa, vuelve a reproducir, hace entrevistas, collages, escribe. Todo debe quedar asentado, todo debe anotarse en el cuaderno, inscribirse en la superficie de las cosas, volverse tangible, material. Como si a fuerza de semejante destrucción, el presente mismo se encontrara en riesgo de desaparecer. Si en Manigua asistimos a la degradación del espacio, Cuaderno de Pripyat lo afirma desde la primera línea: «El hombre regresa al lugar donde nació, después de permanecer en un asentamiento volátil y encuentra que ambos sitios son semejantes, las caras de una misma moneda» (Ríos, 2012:9). Malofienko inicia el camino de regreso a la casa de su infancia y «en su rostro se enciende la decepción de quienes imaginan el regreso a toda orquesta» (10). Regresa al lugar donde nació, cierra los ojos y en su memoria recorre el camino que lo conduce a su casa, guiado por el recuerdo de lo familiar. Ambas imágenes - la del recuerdo y la del presente - se superponen, como una fotografía con doble exposición. En una sola mirada convergen el pasado de lo que fue Pripyat y el presente derruido. Y piensa: «¿Esto es un lugar? Capas incontables de saqueos transformaron la habitación en un espacio simbólico» (10).

El punto de partida es conocido: en abril de 1986 Pripyat explota por los aires y los efectos de la radiación cubren todo lo que habitaba el lugar. El accidente nuclear deja a Malofienko evacuado, en el exilio y desde allí solo queda regresar, recomponer, montar y dar forma al presente. El tiempo después de la destrucción implica el regreso a un espacio que superpone imágenes: un campo visual que 
reúne aquello que ya no está presente y a su vez señala y vuelve visible su propia ausencia. Así es el retorno de Malofienko, una tensión temporal que puja por inscribir en la superficie de las cosas aquello que ya no está. Sin embargo, en este escenario no todo es ausencia, sino que aún quedan restos. La destrucción, afirma Didi-Huberman, «nunca es total aunque sea continua» (2012:65). El tan mentado tiempo después del fin nos indica incesantemente que hay restos materiales, que hay «una verdadera capacidad de resistencia histórica» (36). Así, la destrucción abre paso a la emergencia de un nuevo mundo, colateral al primero pero que comienza a extenderse y que terminará por reemplazarlo. ${ }^{4}$

Pripyat, la ciudad anestesiada, parece llevar la marca de un pasado incumplido y en la figura de Malofienko, confirmamos que allí solo quedan restos. Ríos despliega un territorio en ruinas, sepultado, delimitado por el abandono. En la ciudad adormecida, Malofienko parece un sonámbulo que vaga entre los desechos intentando reconstruir allí un sentido perdido. La tensión que tiene lugar entre la recomposición (de los restos, de la ciudad, de la historia, de la memoria) y la propia imposibilidad de hacerlo (la fragmentariedad como principio constitutivo de la ruina, de la imagen, del presente) se torna central en la escritura de Ríos: «Algo dibuja el pensamiento, por el momento son materiales imposibles de organizar» (2012:13).

Además, la escritura de Ríos se detiene en la mirada y en los objetos. Hay algo en la percepción de Malofienko que no logra terminar de aprehender aquello que observa. La ruina por momentos se torna puramente material, y en otros, su propagación es tal que no consigue capturarse en una imagen. Cuaderno de Pripyat despliega una singular percepción de las cosas, en tanto los materiales que antes signaban la cotidianeidad de la vida, guardan ahora, en este escenario derruido, una cierta extrañeza: «La luz del sol, que en otro país siempre es la misma, dilata en esta región las sombras que ya deberían estar en retirada, esas costras apenas amarillas adheridas a los objetos, apariencias cenagosas en las proximidades del río prohibido» (26).

Asistimos también, como antes mencionamos, al despliegue de una lengua en ruinas, alterada, al borde del olvido. La escritura nos presenta un texto rasgado por otra lengua. Si en Manigua asoma el swahilli, en Pripyat el ucraniano, afirmando en cada una el estado residual de la lengua. Malofienko no solo regresa a un territorio extraño, sino que también regresa para afirmarse ante una lengua que ya no es suya. De las pocas palabras que recuerda, ninguna sirve, le dicen los guías que lo acompañan a recorrer la ciudadela. Esas palabras refieren a un estado de la vida que ya no es tal, que ha desaparecido. Pripyat es el testimonio de una lengua perdida, solo quedan «restos de mampostería verbal» (2012:75). Hasta el propio nombre del personaje se torna inestable: «alguien a quien podríamos llamar, de manera provisoria, Malofienko» (9). Sin embargo, la lengua aún nombra para hacer presente eso que ya no está: «Hay un mínimo homenaje y consiste en nombrarlos para que tarden un poco más en irse de nosotros» (91). La poeta Oksana, a quien Malofienko entrevista, afirma que se siente otra persona cuando habla otra lengua, «otro cuerpo nace o resucita en mí» (22). La lengua en Pripyat, entonces, es la expresión residual de ese mundo desencajado, y también la transfiguración de la dimensión material por efecto de la radiación, aquello que Ríos llama lengua teñida de verde:

La contaminación quema las suelas de los zapatos hasta disolverlas, sin embargo es un asunto al que nadie escandaliza. Así pasan los días que engordan hasta hacerse años. El color verde que tiñe las lenguas de tantos jóvenes como Mariika es visto menos como la secuela de un desastre nuclear que como el orgullo patriótico en el sitio exacto donde la garganta entona el himno de la reconstrucción. (50) 
En las entrevistas que realiza Malofienko, se impone el deseo de un regreso que se torna imposible, se escudriña en la memoria para concluir que solo quedan restos. Así lo registra en el encuentro con la poeta: «Nunca se puede volver, podés volver al lugar geográfico, pero no al tiempo, y lo que uno quiere realmente es volver al tiempo que dejó, y eso es imposible» (22). Sin embargo, esa imposibilidad a la que refiere no es tal al momento de advertir que el regreso toma la forma de imágenes parciales, superpuestas y da lugar a una tensión temporal entre el pasado y el presente: la conformación de un paisaje de escombros como comprobación de eso que ha sido y eso que ha quedado. En otra entrevista, un sobreviviente relata su retorno: frente a una habitación llena de escombros, la presencia de un mapa de Ucrania como el único testimonio de un territorio que ya no existe.

En Pripyat, las formas sobreviven, a pesar de cierta resistencia a la figuración. Los restos de la historia de Malofienko, aquella que con afán intenta reconstruir, parecen asumir la forma de vestigios cuya manifestación apenas es visible, y sin embargo, se encuentran diseminados por todas partes. Como mencionamos, el personaje persigue el propósito de reunir material para realizar un documental y precisamente allí emerge un procedimiento, tanto en el hacer de Malofienko, cuanto en la escritura de Carlos Ríos. Por un lado, Cuaderno de Pripyat se compone a partir del fragmento; sus entradas son diversas: incursiones, entrevistas, amarillo, azul, correspondencia, bronce, dorado y así. Y por el otro, Malofienko hace collages, monta piezas, ensambla como un artista vanguardista: «Encuentra unas figuras de caballos en las revistas sustraídas en las salas de espera de Kloten. Recorta y pega en las láminas anexas al cuaderno» (2012:28). Y en otro pasaje leemos: «Y así ensambla, durante horas, con manía constructivista, escenarios probables» (95). En las ficciones de Ríos el procedimiento opera a partir del fragmento, y nuevamente la presencia de la figura del artista traza la relación entre ruina y montaje: «En presencia de la ruina, trabaja la cita y la repetición» (105), afirma Francine Masiello.

Ríos nos sitúa ante un tiempo que solo es posible leer en la ruina material de los objetos. Asistimos al despliegue de una historia cuyo sentido temporal se ve cuestionado frente a la linealidad de los hechos, para atender a la memoria de las cosas, para hacer emerger las huellas de un pasado aún no clausurado: restos, deshechos, residuos, irrupciones. En la escritura se manifiesta el deseo de una potencia, de un hacer a pesar de la destrucción, o mejor, de un hacer junto a la destrucción.

La destrucción, entonces, nunca es total, aunque sea continua. Aunque aparenta arrasar con todo, allí persisten las huellas de su propio movimiento, restos que insisten en permanecer. Podríamos figurar Pripyat en una imagen: una habitación abandonada, vacía, sin objetos, pero con la presencia de marcas que atestiguan el recuerdo de los objetos que la habitaron. Como si corriéramos un mueble y advirtiéramos allí, en la pared, la mancha oscura que dibuja sus contornos:

Observa las marcas de los artefactos familiares en las paredes. Si cierra los ojos, recupera en su mente cada mueble tal como los había visto en su infancia. Al abrirlos de golpe, la imagen mental se imprime en el espacio vacío y aparece, por un instante, la sustancia filial que el destazador ha perdido para siempre. (Ríos, 2012:63)

La superficie de la pared se vuelve soporte sobre el que inscribe eso que ya no está. Y nos indica, como una marca insistente en las ficciones de Ríos que, ante la destrucción, la ruina se torna una imagen capaz de leer y actualizar los restos materiales del pasado. 


\section{Notas}

1 Este problema es largamente trabajado en la filosofía, la historia y la crítica. En tanto nuestro recorrido no busca reponer esta discusión, sí nos interesa al menos mencionar el punto decisivo que conforman las tesis Sobre el concepto de historia (2009) de Walter Benjamin, y la relectura y actualización atenta que realizan Giorgio Agamben (sobre lo contemporáneo y lo intempestivo) y Georges Didi-Huberman (sobre el anacronismoy la supervivencia).

2 Francine Masiello, en «Los sentidos y las ruinas» (2008) trabaja la relación entre literatura argentina contemporánea y ruina e insiste en este punto. Siendo la ruina el tropo decimonónico por excelencia, es posible que su reaparición en el escenario contemporáneo responda a una experiencia renovada del tiempo. Si el romanticismo se abocó a la contemplación melancólica, la contemporaneidad se entrega a los fragmentos de las ruinas, abandonando la premisa de la totalidad.

3 Manigua comienza con un epígrafe que resonará a lo largo de la novela. Advertimos en la primera página una entrada de la RAE con la definición del término: «manigua. / (Voz taína) / 1. f. Abundancia desordenada de algo, confusión, cuestión intrinca-

da. / 2. f. Ant. Conjunto espeso de hierbas y arbustos tropicales. / 3. f. Col. Bosque tropical pantanoso e impenetrable. / 4. f. Hond. y Nic. Terreno, con frecuencia pantanoso, cubierto de espesa maleza tropical».

4 Nuevamente, el epígrafe en las novelas de Ríos conforma una línea de lectura que se expande a lo largo de la lectura. Cuaderno de Pripyat comienza con dos citas. Una de ellas, a la que hacemos referencia, es de Saer y dice: «Es verdad que las cosas, durante esa primavera - la explosión había sido en abrileran, por su tamaño, su color o su forma, un poco diferentes de lo que siempre habían sido, como si a causa de la explosión un nuevo mundo, colateral del primero, hubiese comenzado a proliferar». En plena consonancia con este fragmento, la novela de Ríos explora no la refundación de un nuevo mundo producto del desastre, ni el corte radical que supone el imaginario del fin, sino antes bien la convivencia de ambos mundos, el anterior y el posterior a la catástrofe, la concomitancia temporal y espacial, la contaminación podría decir, que tiene lugar allí y que logra interrumpir el diagnóstico decadente del fin.

\section{Referencias bibliográficas}

Agamben, G. (2011). ¿Qué es lo contemporáneo? Desnudez. Buenos Aires: Adriana Hidalgo, 17-29.

Antelo, R. (2016). A ruinología. Florianópolis: Cultura e Barbárie.

(2018). Rastros: ruinas de ruinas. Boca de sapo, XIX(27), 1-11.

Benjamin, W. (2010). Excavar y recordar. Obras. Libro IV, vol. 1. Madrid: Abada.

Blackmore, L. (2017). Ruinas modernas y arte contemporáneo. El caso de El Helicoide de la Roca Tarpeya.

Cuadernos de Literatura, XXI(42), 255-277.

Cadava, E. (2015). La imagen en ruinas. Santiago de Chile: Palinodia.

Cámara, M. (2017). Restos épicos. La literatura y el arte en el cambio de época. Buenos Aires: Libraria.

Catalin, M. (2018). Un final/el final. Cuadernos de Pripyat de Carlos Ríos. Anclajes, XXII(2), 21-34.

Didi-Huberman, G. (1997). Lo que vemos, lo que nos mira. Buenos Aires: Manantial. (2012). Supervivencia de las luciérnagas. Madrid: Abada.

Jouannais, J-Y. (2017). El uso de las ruinas. Retratos obsidionales. Barcelona: Acantilado.

Lazzara, M. y Unruch, V. (2009). Telling ruins in Latin America. Nueva York: Palgrave Macmillan.

Masiello, F. (2008). Los sentidos y las ruinas. Iberoamericana, VII(30), 103-112.

(2012). En los bordes del cráter(sobre la generación del noventa en Argentina). Cuadernos de Literatura, XVI(31), 79-104.

Quintana, I. (2018). Restos y ruinas en el arte latinoamericano contemporáneo. Boca de sapo, XIX(27), 24-29.

Ríos, C. (2009). Manigua. Buenos Aires: Entropía.

(2012). Cuaderno de Pripyat. Buenos Aires: Entropía. 
Rodríguez Freire, R. (2015). Sin retorno. Variaciones sobre archivo y narrativa latinoamericana. Buenos Aires: La cebra.

Simmel, G. (2001). Filosofía del paisaje. El individuo y la libertad. Buenos Aires: Península, 265-282.

Speranza, G. (2017). Cronografías. Artes y ficciones de un tiempo sin tiempo. Barcelona: Anagrama.

Wajcman, G. (2001). El objeto del siglo. Buenos Aires: Amorrortu. 